\title{
Re-examining the relationship between invasive lionfish and native grouper in the Caribbean
}

Biotic resistance is the idea that native species negatively affect the invasion success of introduced species, but whether this can occur at large spatial scales is poorly understood. Here we re-evaluated the hypothesis that native large-bodied grouper and other predators are controlling the abundance of exotic lionfish (Pterois volitans/miles) on Caribbean coral reefs. We assessed the relationship between the biomass of lionfish and native predators at 71 reefs in three biogeographic regions while taking into consideration several cofactors that may affect fish abundance, including among others, proxies for fishing pressure and habitat structural complexity. Our results indicate that the abundance of lionfish, large-bodied grouper and other predators were not negatively related. Lionfish abundance was instead controlled by several physical site characteristics, and possibly by culling. Taken together, our results suggest that managers cannot rely on current native grouper populations to control the lionfish invasion. 
1 Abel Valdivia $^{1 *}$, John F. Bruno ${ }^{1}$, Courtney E. Cox ${ }^{1}$, S. Hackerott ${ }^{1}$, Stephanie J. Green ${ }^{2}$

$2 \quad{ }^{1}$ Department of Biology, The University of North Carolina at Chapel Hill, Chapel Hill, NC

327599, USA

$4 \quad{ }^{2}$ Department of Zoology, Oregon State University, Oregon, USA

$5 \quad$ *corresponding author: abel.valdivia@unc.edu

\section{Introduction}

7 Biotic resistance describes the capacity of native or resident species in a community to

8 constrain the success of invasive species (Elton, 1958). While there are several examples of

9 native species controlling invasive populations, especially invasive plants (Reusch \& Williams,

10 1999; Mazia et al., 2001; Magoulick \& Lewis, 2002; Levine et al., 2004; Mitchell et al., 2006),

11 less clear are the ecological mechanisms that allow heterogeneous communities to resist invasion

12 (Lockwood et al., 2005; Melbourne et al., 2007), and whether these processes are strong enough

13 to compromise invasion success on a large scale (Byers \& Noonburg, 2003; Davies et al., 2005).

14 Especially elusive is whether native predators or competitors can constrain the expansion of

15 exotic predator species at large spatial scales (but see, deRivera et al., 2005). Although biotic

16 resistance substantially reduces the establishment of invaders, there is little evidence that species

17 interactions such as predation completely prevent invasion (Levine et al., 2004; Bruno et al.,

18 2005)

19 The invasion of Pacific lionfishes (Pterois volitans and Pterois miles) into the Caribbean

20 basin (Schofield, 2009) over the past ten years provides an example of biotic interactions within a

21 system that have been unable to reduce exotic invasion at a regional scale (Hackerott et al.,

22 2013). Lionfish have spread to every shallow and deep habitat of the Western North Atlantic and

23 the Caribbean (Whitfield et al., 2007; Betancur-R et al., 2011) including fore reef and patch reef

24 environments (Green \& Côté, 2009; Albins \& Hixon, 2011), seagrass meadows (Claydon et al., 
25 2012), mangrove root forests (Barbour et al., 2010), estuarine habitats (Jud et al., 2011), and even

26 depths of $\sim 90$ meters (Green, pers. obs.). Lionfish dissemination in the region has added

27 additional stress (Albins \& Hixon, 2011; Lesser \& Slattery, 2011; Côté et al., 2013) to an already

28 disturbed coral reef ecosystem (Paddack et al., 2009; Schutte et al., 2010). Their voracious

29 appetite threatens small reef fish and juveniles of depleted fish populations including

30 commercially important species such as groupers and snappers, and keystone grazers such as

31 parrotfishes (Albins \& Hixon, 2008; Green et al., 2012). The failure of the system to constrain

32 invasion success may be associated in part to the lack of native predatory capacity due to

33 overfishing (Carlsson et al., 2009; Mumby et al., 2011), or weak biotic resistance by the native

34 predators and competitors (Levine et al., 2004).

35 The first study to investigate the potential for biotic control of lionfish by native predators

36 found an inverse relationship between the biomass of native groupers and lionfish on reefs at the

37 Exuma Cays Land and Sea Park (ECLSP) in the Bahamas (Mumby et al., 2011). Specifically,

38 Mumby et al. (2011) found that grouper biomass could explain $\sim 56 \%$ of the variability in lionfish

39 biomass, and concluded that large-bodied groupers can constrain lionfish abundance if a series of

40 cofactors at the site level are kept constant (i.e., reef complexity, larval supply, habitat

41 characteristics). To examine whether this relationship holds true at a scale that reflects the

42 heterogeneity of Caribbean reefs, Hackerott et al. (2013) gathered data on lionfish and grouper

43 abundance from 71 sites across multiple regions in the Caribbean. When accounting for several

44 site-specific covariates, Hackerott et al. (2013) did not find a relationship between the abundance

45 of lionfish and native predators/competitors at a broad spatial scale in the Caribbean.

46 Aside from the suite of variables considered by Hackerott et al. (2013), several other

47 covariates that are known to affect fish community structure, but vary across the region, could

48 mask the effect native predators have on lionfish abundance. Accounting for spatial scale and

49 potential cofactors is essential when evaluating the importance of any single variable in a spatial 
comparative study (MacNeil et al., 2009). In particular, fishing mortality, larval dispersal, habitat

51 quality, connectivity, reef structural complexity, depth, ecological interactions, and a myriad of

52 other factors control the population dynamics of reef fish species (Sale, 2002). Here we re-

53 evaluated the relationship between large-bodied grouper and other predators and lionfish

54 abundance, accounting for a broader set of covariates than those included by Hackerott et al.

55 (2013) that may mediate the interaction between predators and the invader (Mumby et al.,

56 2013).We also evaluated the grouper bio-control hypothesis proposed by Mumby et al. (2011)

57 and provide new insights into how such biotic resistance is unlikely at the scale of the Caribbean

58 reef system. The issue still remains how to best manage and/or reduce numbers of lionfish where

59 they are currently found, and the only effective solution to date is direct removal by fisherman

60 and divers (Barbour et al., 2011; Frazer et al., 2012; Green et al., 2013 in press).

\section{Materials and Methods}

\section{Sites and fish surveys}

Survey methods are explained in detail in Hackerott et al., (2013). In summary, we surveyed 71 coral reefs (3-15 m deep) across three distinct reef habitats (spur-and-grove, slope, and patch reef) in three regions of the Caribbean: The Bahamas, Cuba, and the Mesoamerican Barrier Reef (Belize and Mexico) from 2009 to 2012 (Fig. S1, Table S1). All these habitats were

67 once dominated by the coral complex Montastraea/Orbicella (Edmunds \& Elahi, 2007). Reef sites were selected to cover a wide range of reef fish abundance. To survey fish abundance, we

69 conducted underwater visual censuses at each site using belt transects (for spur-and-grove and

70 slopes) or roving survey dives (for patch reef) (see details in Hackerott et al., 2013). Fish biomass

71 was calculated through the allometric length-weight conversion formula (Froese \& Pauly, 2013)

72 and scaling parameters for lionfish were obtained elsewhere (Green et al., 2011). Grouper was

73 defined as the combined biomass of relatively large-bodied species such as Nassau (Epinephelus 
74 striatus), tiger (Mycteroperca tigris), black (Mycteroperca bonaci), and yellowfin grouper

75 (Epinephelus intersticialis) as defined also by Mumby et al., (2011). These species could

76 potentially prey on lionfish (Maljković et al., 2008; Mumby et al., 2011) and are relatively more

77 abundant than other potential predators in the region (Hackerott et al., 2013). Other predators

78 considered in this study included any species that could potentially prey on lionfish (see Table S2

79 in Hackerott et al., 2013). To directly compare our study with the generality of the results by

80 Mumby et al. (2011), we overlaid their values of fish biomass on our main biomass plot and

81 added boxplots that described the distribution of both data sets.

\section{Covariates}

The site-specific parameters included as covariates in our statistical model were wind exposure, habitat type, protection status, depth, and time since invasion which are described in detail in Hackerott et al. (2013). We added two new variables to the models that are hypothesized to strongly modulate lionfish abundance (Mumby et al., 2013): human population density/reef area (humans/reef) which is a proxy for fishing effects (Newton et al., 2007; Mora, 2008), and is predicted to be negatively correlated with lionfish density; and reef complexity, which is a proxy

89 for habitat heterogeneity within sites, predicted to have a positive effect on lionfish density

90 (Green et al., 2012). Human population density was calculated as the number of humans within

$9150 \mathrm{~km}$ (maximum number of people living within $50 \mathrm{~km}$ radius of each site). We chose $50 \mathrm{~km}$

92 because it is a reasonable range of human influence on Caribbean reefs (Mora, 2008). Estimates

93 of human population counts for the year 2010 were obtained from the Gridded Population of the

94 World V.3 at 0.25 degree resolution (SEDAC, 2010). Reef area was calculated within $10 \mathrm{~km}$

95 radius of each site, well below the average home range for certain predators species (Farmer \&

96 Ault, 2011). Reef area was calculated from the Global Distribution of Coral Reefs (2010)

97 database as available at the Ocean Data Viewer (http://data.unep-wcmc.org/datasets/13). This

98 database represents the global distribution of warm-water coral reefs compiled mostly from the 
Millennium Coral Reef Mapping Project (UNEP-WCMC et al., 2010). All spatial calculations were done in ArcGIS v10.0. Humans/Reef Area (humans $/ \mathrm{km}^{2}$ of reef) was defined as: Number of humans within $50 \mathrm{~km} /$ Reef area within $10 \mathrm{~km} /\left(\pi 10^{2}\right)\left(\mathrm{km}^{2}\right)$

To estimate reef complexity we used a rugosity index (0-5) estimated at the transect level, where " 0 " was a flat substrate with no vertical relief and " 5 " was an exceptionally complex substrate with numerous caves and overhangs (Polunin \& Roberts, 1993). Relief complexity for Eleuthera and New Providence sub-regions was estimated by averaging measurements of reef height (i.e., the vertical distance between the lowest and highest point of the reef structure in $\mathrm{cm}$ ), taken at five haphazard points within the survey area (either transect or rover diver area) (Wilson et al., 2007). To make reef complexity estimates homogenous for all sites, we transformed the relief complexity estimates taken in Eleuthera and New Providence to the rugosity index, described by Polunin \& Roberts (1993), by assigning a gradient of $0 \mathrm{~cm}$ to " 0 " and over $300 \mathrm{~cm}$ to "5". This resulted in a continuous rugosity index for these two sub-regions that was comparable with the rest of the sites.

\section{Data analysis}

Before applying the statistical model, we explored the data and determined that a negative binomial or Poisson were the most plausible distributions for lionfish counts (Appendix). Additionally, we checked for collinearity among covariates. We ran a logistic regression model with all the covariates and examined the variance inflation factor (VIF) for each variable. We used a VIF $>2$ as a threshold to determine collinearity (Graham, 2003). Depth was correlated with reef habitat type as shallower sites tended to be dominated by patch reefs. Thus we modeled these two factors separately. However, we found that keeping depth in the full model, together with habitat type, did not compromise fitting or the magnitude of the effects (Appendix).

123 Model Builder (glmmADMB) package (Skaug et al., 2013) in R 3.0.2 (R Core Team, 2013). As 
124 the lionfish data were over-dispersed and with excess of zeroes (Hackerott et al., 2013), a

125 glmmADMB which accommodates zero inflation was the most adequate model structure (Bolker

126 et al., 2012). We modeled lionfish counts with a negative binomial type 1 distribution and log

127 link because this model performed better than a Poisson distribution based on the Akaike

128 Information Criterion (AIC) (Appendix). Since a negative binomial is a discrete distribution we

129 included an offset in the model to account for survey area (sampling unit level), thus we could

130 effectively analyze the relationship between the density of lionfish and grouper biomass, i.e.:

$131 \quad \log ($ LF Density $)=\log ($ LF Counts $)-\log ($ Survey Area)

132 Because lionfish density and biomass were highly correlated (Pearson's product moment

133 correlation $\sim 0.96, \mathrm{p}<0.0001$, Appendix), the results of the model should be applicable to biomass

134 as well. The rest of the covariates were considered fixed. We standardized and centered the

135 numerical covariates to aid in comparison of the coefficient estimates. To account for spatial

136 autocorrelation we nested sites within sub-regions and used them as random effects (see Table S1

137 for sub-regions). To validate the model we corroborated that no patterns were found on the plot of

138 the model residuals versus fitted values.

139 Moran's I similarity spline correlograms constructed from the residuals of the

140 glmmADMB model (Zuur et al., 2009) graphically indicated that our mixed-effect modeling

141 framework successfully accommodated the spatial autocorrelation observed in the raw data (Fig

142 S2). Additionally, we used Mantel tests (Mantel, 1967) to confirm the lack of spatial

143 autocorrelation between the Pearson residuals of the model and the lag distance (in $\mathrm{km}$ ) between

144 sites (i.e., whether sites that are closer together were more similar), and found that the overall

145 correlation coefficient for the model was low $(r=0.073, p=0.0001)$. We performed the

146 autocorrelation analyses using the spatial nonparametric covariance function (ncf) package

147 version 1.1-5 (BjØrnstad, 2013). All analyses were performed in R version 3.0.2 (R Core Team,

148 2013). Additionally, we provide the entire workflow R code (Appendix) and the master data 
summary by site level (FigShare, http://dx.doi.org/10.6084/m9.figshare.899210).

\section{Results and Discussion}

151 Even when including proxies for fishing and habitat structure in our statistical model, we

152 found no support for an effect of large-bodied grouper or other predator biomass on lionfish

153 abundance (Fig. 1, Table S3). As in Hackerott et al. (2013), the effects of other covariates in our

154 analysis (namely wind exposure, habitat type, and protection status) (Fig. 1) remained the

155 principal factors that appear to influence lionfish abundance. Our analyses suggest that variation

156 in lionfish density across the region is driven by environmental processes and human activity and

157 not by biotic resistance from native predators.

158 The absence of a relationship between lionfish and native grouper biomass across a large

159 scale suggests that the results of Mumby et al. (2011), which found a negative association across

16012 sites - 5 inside and 7 adjacent to a no-take reserve (ECLSP) - represented a subset of a much

161 broader and complicated relationship driven by other factors (Fig. 1 and 2). The average biomass

162 of large-bodied grouper in our study of the Caribbean region $\left(7.6 \pm 0.8 \mathrm{gm}^{-2}\right.$, mean \pm standard

163 error) was slightly lower (Wilcoxon test, $\mathrm{W}=1197, \mathrm{p}=0.002$ ) than that found by Mumby et al.

164 (2011) at Exuma (10.0 $\left.\pm 2.6 \mathrm{gm}^{-2}\right)$ (Fig. 2). In contrast, the average biomass of lionfish in our

165 study $\left(7.8 \pm 0.5 \mathrm{gm}^{-2}\right.$ ) was $\sim 20$ times higher (or $\sim 2$ times higher excluding patch reefs, i.e., $0.7 \pm$

$\left.1660.1 \mathrm{gm}^{-2}\right)$ than those found at Exuma $\left(0.4 \pm 0.1 \mathrm{gm}^{-2}\right)$ by Mumby et al. (2011) (Fig. 2). In that

167 study, relatively low lionfish biomass $\left(\sim 0.3 \mathrm{gm}^{-2}\right)$ was associated with relatively high grouper

168 biomass $\left(\sim 25 \mathrm{gm}^{-2}\right)$. However, across 71 sites in our study, lionfish biomass ranged widely $(0-50$

$169 \mathrm{gm}^{2}$ ) at sites with equivalent grouper abundance (Fig. 2). Thus, while predators may negatively

170 impact lionfish under a particular set of local conditions (Mumby et al., 2011), the underlying

171 relationship between lionfish and predator biomass was undetectable on a wide range of

172 heterogeneous sites across the Caribbean region. 
174 capacity resulting from a high frequency of large individuals (Fig. 3a). Grouper at protected sites

175

176

177

178

179

180

181

182

183

184

185

186

were, on average, larger $(48.6 \pm 1.5 \mathrm{~cm} \mathrm{TL}$, mean \pm standard error total length $)$ than those at unprotected sites $(34.7 \pm 1.1 \mathrm{~cm})(\mathrm{t}=-7.68, \mathrm{p}<0.001$, Fig. 3a). It is unlikely that sites with relatively high grouper biomass have low predatory capacity as a result of more abundant, but smaller, individual fishes. Indeed, the exact opposite pattern is well documented in a wide range of habitat types for several fish species (Gust et al., 2001; Friedlander \& DeMartini, 2002; McClanahan et al., 2007). This seems to also be the case for groupers in our study (Fig. 3b). At sites with grouper biomass of at least $10 \mathrm{gm}^{-2}$, which was the minimum biomass per site in the ECLSP (Mumby et al., 2011), there were relatively high frequencies of medium/large individuals (Fig. 3b). Medium/large groupers ( $>30 \mathrm{~cm}$ TL) have been classified as having potentially high predatory capacity (Mumby et al., 2011). We found relatively lower frequencies $(<50 \%)$ of small individuals $(<30 \mathrm{~cm}$ TL) across all protected sites. Therefore, it is unlikely that a lack of predatory capacity at sites with the highest grouper biomass (Fig. 2 and Fig. 3b) explains the absence of a relationship between lionfish and grouper in our results.

While we did not find evidence for an effect of native predators on invasion status, lionfish biomass varied significantly between the reef types we examined. All of our fore-reef sites (slope and spur-and-groove) constituted high-profile habitats and we also included a set of patch reefs, a reef habitat common in the region. In particular, slope and spur-and-groove habitat had a negative effect on lionfish abundance (Fig. 1, Table S3) with higher average lionfish abundance in patch reef habitats $\left(27.5 \pm 2.1 \mathrm{gm}^{-2}\right.$ vs. $\left.0.7 \pm 0.1 \mathrm{gm}^{-2}\right)$. However, both lionfish and large-bodied grouper and predators were frequently observed in each of these habitats (Fig. 3c).

The class size distribution for groupers among reef habitats were similar (Fig. 3c). Almost 90\% of the patch reef sites had groupers in the $21-40 \mathrm{~cm}$ class size range, while $\sim 60 \%$ of slope and spurand-groove sites had groupers within 31-50 cm total length (Fig. 3c). Although, the size 
198 distribution of our study sites indicates that grouper $>30 \mathrm{~cm}$ TL (deemed 'large-bodied' by

199 Mumby et al. 2011) were frequently (over 50\%) observed in patch reef habitats (Fig. 3c), we

200 caution that other patch reefs across the Caribbean must be surveyed in order to make meaningful

201 extrapolations of the observed patterns in this habitat.

202 Other variables may also partly explain the variability of lionfish abundance in the region.

203 Wind exposure, specifically whether sites were located on the windward side, had a weak

204 negative effect on lionfish abundance (Fig. 1). However, the mechanism behind this association is

205 not well understood and a premature explanation may be misleading. Larval supply, which we

206 did not measure, may contribute to the lack of biotic resistance. As with other reef fish species

207 (James et al., 2002; Cowen \& Sponaugle, 2009), differential larval supply could influence site-

208 specific lionfish recruitment (Ahrenholz \& Morris, 2010). However, such data are not available

209 for our sites. While measuring larval supply would have been interesting, it was outside the scope

210 of our study due to the large number of sites included and the regional scale of the analysis.

211 Additionally, though larval supply can be predicted by biophysical models that describe

212 oceanographic features such as wind direction, surface temperature, or tidal amplitude, these

213 relationships are often taxon-dependent (Wilson \& Meekan, 2001; Vallès et al., 2009).

214 The question from a management point of view is whether native predators can actually

215 constrain lionfish abundance across the Caribbean, given the heterogeneity of the systems and the

216 factors that seemingly affect lionfish abundance. While we found no evidence that large-bodied

217 grouper or any other large-bodied predators influence lionfish invasion success across the region,

218 this finding is expected based on other systems and examples of invasive predators. For example,

219 there is weak support in the literature for the biotic resistance hypothesis of native species

220 constraining exotic predators in natural ecosystems, and rarely can resident predators constrain

221 the distribution expansion of the invader (Harding, 2003; deRivera et al., 2005). In fact, the exact

222 opposite is typical in systems where native predators are abundant. For example, the successful 
223 invasion of the Burmese python (Python molurus bivittatus) in the Everglades of South Florida

224 has not been constrained by potential and abundant predators such as alligators (Alligator

225 mississippiensis) (Willson et al., 2011). Moreover, it is common that invasive predators feed on

226 the juveniles of the resident predators and competitors (Snyder \& Evans, 2006; MacDonald et al.,

227 2007; Doody et al., 2009; Kestrup et al., 2011; Willson et al., 2011; Côté et al., 2013), further

228 weakening the potential resistance capacity of the system. Ecological interactions, such as

229 predation and competition, seldom enable communities to resist invasion, but instead constrain

230 the abundance of invasive species once they have successfully established (Levine et al., 2004).

231 However, the abundance of lionfish across the region does not appear to be constrained by

232 ecological interactions (Hackerott et al., 2013). In the one published record of grouper eating

233 lionfish (Maljkovic et al., 2008), it could not be determined whether the lionfish were dead or

234 alive when consumed. It is common for divers and tour operators to feed speared lionfish to

235 native predators, including sharks (Busiello, 2011). However, there is no evidence that this

236 practice has changed the natural predatory instincts of resident predators towards the invader and

237 feeding speared lionfish to native predators is now being discouraged due to safety concerns for

238 divers (Whittaker, 2013).

239 Our results indicate that protection status (i.e., whether sites were located within a marine

240 reserve or not) also had a negative effect on lionfish abundance (Fig. 1). This is most likely due to

241 targeted culling in protected areas. Morris and Whitfield (2009) suggested that lionfish removals

242 should be focused on ecologically important areas, including marine protected areas and reserves.

243 Lionfish removals have since occurred in many marine reserves through organized citizen

244 programs (Biggs \& Olden, 2011; López-Gómez et al., 2013) and by reef managers (author pers.

245 comm. with Belize Audubon Society). This effort is paying off and has the potential to greatly

246 reduce lionfish abundance, at least temporarily (Barbour et al., 2011; Frazer et al., 2012; Côté et

247 al., 2013). In our dataset, of the six sites with grouper biomass over $20 \mathrm{gm}^{-2}$, five were in 
248 protected areas where culling is very likely occurring (Fig. 2). This pattern supports the results of

249 our statistical analysis that lionfish abundance is reduced in marine protected areas due to some

250 factor other than predator abundance. The negative effect of protection status on lionfish

251 abundance and lack of effect of grouper or other predator biomass on lionfish abundance indicate

252 that culling within protected areas most likely explains the observed pattern.

253 This analysis expands our original statistical model of the relationship between invasive

254 lionfish and native grouper species (Hackerott et al., 2013) to include two additional covariates

255 hypothesized to moderate the relationship between these species (Mumby et al. (2013). After

256 accounting for these additional processes, we find that: (a) the biomasses of lionfish and large-

257 bodied grouper (or other predators) are not negatively related, and (b) lionfish biomass is

258 controlled by a number of physical site characteristics, as well as by culling within marine

259 reserves. Our study was motivated by the desire to explore whether the findings and solutions

260 from local case studies will be effective elsewhere, which is key to informed management

261 decisions about the invasion. We conclude that removals are most likely the only feasible

262 mechanism for controlling lionfish at a Caribbean-wide scale.

\section{Grant Disclosures}

264 National Science Foundation (OCE-0940019 to JFB), National Geographic Society Committee

265 for Research and Exploration (grant 8514-08 to JFB)

\section{Funding}

267 This work was funded in part by the National Science Foundation, the National Geographic

268 Society Committee for Research and Exploration, the Royster Society Carol and Edward

269 Smithwick Dissertation Fellowship (to AV), the Rufford Small Grants Foundation (to CEC), the 
David H. Smith Conservation Research Fellowship (to SJG), and the University of North

271 Carolina at Chapel Hill. The funders had no role in study design, data collection and analysis, 272 decision to publish, or preparation of the manuscript.

\section{Acknowledgements}

274 We thank F. Pina for logistic support in Cuba. C. Layman, D. Knowles, The Bahamas National

275 Trust and Friends of the Environment provided logistic support in the Bahamas. We thank J.

276 Pawlik, M. Marti, and L. Deagan for their help and facilitation of a research expedition to

277 Mexico. We thank the Belize Fisheries Department, the Southern Environmental Association,

278 Healthy Reefs Initiative and the Toledo Institute for Development and Environment for support in

279 Belize. We thank the Academic editor of PeerJ, Michael Somers, and reviewers Charles Griffiths

280 and Joseph Pawlik for commenting on this manuscript.

\section{Permits}

282 Bahamas: Department of Marine Resources, Ministry of Agriculture and Marine Resources.

283 Permit MAF/FIS/17. Cuba: Centro de Control y Inspección Ambiental, Cuba via Fabian Pina.

284 Mexico: Dirección General de Ordenamiento Pesquero y Acuicola de la Comisión Nacional de

285 Acuicultura y Pesca (CONAPESCA) de la Secretaría de Agricultura, Ganaderia, Desarrollo

286 Rural, Pesca y Alimentación (SAGARPA). Permiso DAPA/2/06504/110612/1608. Belize: Belize

287 Fisheries Department. Permit \# 000028-11.

\section{References}

289 Ahrenholz DW, Morris JA. 2010. Larval duration of the lionfish, Pterois volitans along the

290 Bahamian Archipelago. Environmental Biology of Fishes. 88(4):305-309.

291 Albins M, Hixon M. 2011. Worst case scenario: potential long-term effects of invasive predatory 292 lionfish (Pterois volitans) on Atlantic and Caribbean coral-reef communities. Environmental 
294 Albins MA, Hixon MA. 2008. Invasive Indo-Pacific lionfish Pterois volitans reduce recruitment

295 of Atlantic coral-reef fishes. Marine Ecology Progress Series. 367:233-238.

296 Barbour AB, Allen MS, Frazer TK, Sherman KD. 2011. Evaluating the potential efficacy of 297 invasive lionfish (Pterois volitans) removals. PLoS ONE. 6(5):e19666.

298 Barbour AB, Montgomery ML, Adamson AA, Díaz-Ferguson E, Silliman BR. 2010. Mangrove 299 use by the invasive lionfish Pterois volitans. Mar Ecol Prog Ser. 401:291-294.

300 Betancur-R R, Hines A, Acero P. A, Ortí G, Wilbur AE, Freshwater DW. 2011. Reconstructing the 301 lionfish invasion: insights into Greater Caribbean biogeography. Journal of Biogeography.

302 38(7):1281-1293.

303 Biggs CR, Olden JD. 2011. Multi-scale habitat occupancy of invasive lionfish (Pterois volitans) 304 in coral reef environments of Roatan, Honduras. Aquatic Invasions. 6(3):447-453.

305 BjØrnstad ON. 2013. ncf: Spatial nonparametric covariance functions. $R$ package version 1.1-5.

306 Bolker B, Skaug H, Magnusson A, Nielsen A. 2012. Getting started with the glmmADMB 307 package. 12 pp., URL: http://glmmadmb.r-forge.r-project.org/glmmADMB.pdf.

308 Bruno J, Fridley J, Bromberg K, Bertness M. 2005. Insights into biotic interactions from studies 309 of species invasions. Species invasions: insights into ecology, evolution and biogeography. 1331040.

311 Busiello A. 2011. Pictures: Sharks taught to hunt alien lionfish. National Geographic. URL: 312 http://news.nationalgeographic.com/news/2011/03/pictures/110404-sharks-lionfish-alien-fish313 invasive-species-science/

314 Byers JE, Noonburg EG. 2003. Scale dependent effects of biotic resistance to biological invasion. 315 Ecology. 84(6):1428-1433.

316 Carlsson NO, Sarnelle O, Strayer DL. 2009. Native predators and exotic prey -an acquired taste? 317 Frontiers in Ecology and the Environment. 7(10):525-532.

318 Claydon JAB, Calosso MC, Traiger SB. 2012. Progression of invasive lionfish in seagrass, 319 mangrove and reef habitats. Marine Ecology Progress Series. 448:119-129.

320 Côté IM, Green SJ, Hixon MA. 2013. Predatory fish invaders: Insights from Indo-Pacific lionfish 321 in the western Atlantic and Caribbean. Biological Conservation. 164:50-61.

322 Cowen RK, Sponaugle S. 2009. Larval dispersal and marine population connectivity. Annual 323 Review of Marine Science. 1(1):443-466.

324 Davies KF, Chesson P, Harrison S, Inouye BD, Melbourne BA, Rice KJ. 2005. Spatial 325 heterogeneity explains the scale dependence of the native-exotic diversity relationship. Ecology. 326 86(6):1602-1610.

327 deRivera CE, Ruiz GM, Hines AH, Jivoff P. 2005. Biotic resistance to invasion: native predator 
328 limits abundance and distribution of an introduced crab. Ecology. 86(12):3364-3376.

329 Doody JS, Green B, Rhind D, Castellano CM, Sims R, Robinson T. 2009. Population-level

330 declines in Australian predators caused by an invasive species. Animal Conservation. 12(1):46-

33153.

332 Edmunds PJ, Elahi R. 2007. The demographics of a 15-year decline in cover of the Caribbean

333 reef coral Montastraea annularis. Ecological Monographs. 77(1):3-18.

334 Elton CS. 1958. The ecology of invasions by plants and animals. Methuen, London. 181pp.

335 Farmer NA, Ault JS. 2011. Grouper and snapper movements and habitat use in Dry Tortugas,

336 Florida. Marine Ecology Progress Series. 433:169-184.

337 Frazer TK, Jacoby CA, Edwards MA, Barry SC, Manfrino CM. 2012. Coping with the Lionfish 338 Invasion: Can Targeted Removals Yield Beneficial Effects? Reviews in Fisheries Science.

339 20(4):185-191.

340 Friedlander AM, DeMartini EE. 2002. Contrasts in density, size, and biomass of reef fishes 341 between the northwestern and the main Hawaiian islands: the effects of fishing down apex 342 predators. Marine Ecology Progress Series. 230:253-264.

343 Froese R, Pauly D. 2013. FishBase. World Wide Web electronic publication (version 10/2013).

344 Graham MH. 2003. Confronting multicollinearity in ecological multiple regression. Ecology. 345 84(11):2809-2815.

346 Green SJ, Côté IM. 2009. Record densities of Indo-Pacific lionfish on Bahamian coral reefs.

347 Coral Reefs. 28(1):107-107.

348 Green SJ, Akins JL, Ct IM. 2011. Foraging behaviour and prey consumption in the Indo-Pacific 349 lionfish on Bahamian coral reefs. Marine Ecology Progress Series. 433:159-167.

350 Green SJ, Akins JL, Maljković A, Côté IM. 2012. Invasive lionfish drive Atlantic coral reef fish 351 declines. PLoS ONE. 7(3):e32596.

352 Green SJ, Dulvy NK, Brooks ALM, Akins JL, Cooper AB, Miller S, Côté IM. 2013. Linking

353 removal targets to the ecological effects of invaders: a predictive model and field test. Ecological 354 Applications.

355 Green SJ, Tamburello N, Miller SE, Akins JL, Côté IM. 2012. Habitat complexity and fish size 356 affect the detection of Indo-Pacific lionfish on invaded coral reefs. Coral Reefs.

357 Gust N, Choat J, McCormick M. 2001. Spatial variability in reef fish distribution, abundance, 358 size and biomass: a multi-scale analysis. Marine Ecology Progress Series. 214:237-251.

359 Hackerott S, Valdivia A, Green SJ, Côté IM, Cox CE, Akins L, Layman CA, Precht WF, Bruno 360 JF. 2013. Native predators do not influence invasion success of Pacific lionfish on Caribbean 361 reefs. (F. Guichard, Ed.)PLoS ONE. 8(7):e68259.

362 Harding JM. 2003. Predation by blue crabs, Callinectes sapidus, on rapa whelks, Rapana venosa: 
363 possible natural controls for an invasive species? Journal of Experimental Marine Biology and 364 Ecology.297(2):161-177.

365 James MK, Armsworth PR, Mason LB, Bode L. 2002. The structure of reef fish metapopulations: 366 modelling larval dispersal and retention patterns. Proceedings of the Royal Society of London.

367 Series B: Biological Sciences. 269(1505):2079-2086.

368 Jud ZR, Layman CA, Lee JA, Arrington DA. 2011. NOTE Recent invasion of a Florida (USA)

369 estuarine system by lionfish Pterois volitans / P. miles. Aquatic Biology. 13(1):21-26.

370 Kestrup ÅM, Dick JTA, Ricciardi A. 2011. Interactions between invasive and native crustaceans: 371 differential functional responses of intraguild predators towards juvenile hetero-specifics.

372 Biological Invasions. 13(3):731-737.

373 Lesser MP, Slattery M. 2011. Phase shift to algal dominated communities at mesophotic depths 374 associated with lionfish (Pterois volitans) invasion on a Bahamian coral reef. Biological 375 Invasions. 13(8):1855-1868.

376 Levine JM, Adler PB, Yelenik SG. 2004. A meta-analysis of biotic resistance to exotic plant 377 invasions. Ecology Letters. 7(10):975-989.

378 Lockwood JL, Cassey P, Blackburn T. 2005. The role of propagule pressure in explaining species 379 invasions. Special issue: Invasions, guest edited by Michael E. Hochberg and Nicholas J. Gotelli. 380 20(5):223-228.

381 López-Gómez MJ, Aguilar-Perera A, Perera-Chan L. 2013. Mayan diver-fishers as citizen 382 scientists: detection and monitoring of the invasive red lionfish in the Parque Nacional Arrecife 383 Alacranes, southern Gulf of Mexico. Biological Invasions. 1-7.

384 MacDonald JA, Roudez R, Glover T, Weis JS. 2007. The invasive green crab and Japanese shore 385 crab: behavioral interactions with a native crab species, the blue crab. Biological Invasions. 386 9(7):837-848.

387 MacNeil MA, Graham NAJ, Polunin NVC, Kulbicki M, Galzin R, Harmelin-Vivien M, Rushton 388 SP. 2009. Hierarchical drivers of reef-fish metacommunity structure. Ecology. 90(1):252-264.

389 Magoulick DD, Lewis LC. 2002. Predation on exotic zebra mussels by native fishes: effects on 390 predator and prey. Freshwater Biology. 47(10):1908-1918.

391 Maljković A, Leeuwen TEV, Cove SN. 2008. Predation on the invasive red lionfish, Pterois

392 volitans (Pisces: Scorpaenidae), by native groupers in the Bahamas. Coral Reefs. 27(3):501-501.

393 Maljkovic A, van Leeuwen TE, Cove SN. 2008. Predation on the invasive red lionfish, Pterois 394 volitans (Pisces : Scorpaenidae), by native groupers in the Bahamas. Coral Reefs. 27:501-501.

395 Mantel N. 1967. The detection of disease clustering and a generalized regression approach.

396 cancer research. 27(2 Part 1):209-220.

397 Mazia NC, Chaneton EJ, Ghersa CM, León RJ. 2001. Limits to tree species invasion in pampean

398 grassland and forest plant communities. Oecologia. 128(4):594-602. 
399

400

401

402

403

404

405

406

407

408

409

410

411

412

413

414

415

416

417

418

419

420

421

422

423

424

425

426

427

428

429

430

431

432

433

434

435

McClanahan TR, Graham NAJ, Calnan JM, MacNeil MA. 2007. Toward pristine biomass: reef fish recovery in coral reef marine protected areas in Kenya. Ecological Applications. 17(4):10551067.

Melbourne BA, Cornell HV, Davies KF, Dugaw CJ, Elmendorf S, Freestone AL, Hall RJ, Harrison S, Hastings A, Holland M, Holyoak M, Lambrinos J, Moore K, Yokomizo H. 2007. Invasion in a heterogeneous world: resistance, coexistence or hostile takeover? Ecology Letters. 10(1):77-94.

Mitchell CE, Agrawal AA, Bever JD, Gilbert GS, Hufbauer RA, Klironomos JN, Maron JL, Morris WF, Parker IM, Power AG, Seabloom EW, Torchin ME, Vázquez DP. 2006. Biotic interactions and plant invasions. Ecology Letters. 9(6):726-740.

Mora C. 2008. A clear human footprint in the coral reefs of the Caribbean. Proceedings of the Royal Society B: Biological Sciences . 275 (1636):767-773.

Morris JA, Akins JL. 2009. Feeding ecology of invasive lionfish (Pterois volitans) in the Bahamian archipelago. Environmental Biology of Fishes. 86(3):389-398.

Mumby PJ, Brumbaugh DR, Harborne AR, Roff G. 2013. On the relationship between native grouper and invasive lionfish in the Caribbean. PeerJ PrePrints 45

Mumby PJ, Harborne AR, Brumbaugh DR. 2011. Grouper as a natural biocontrol of invasive lionfish. PLoS ONE. 6(6):e21510.

Newton K, Côté IM, Pilling GM, Jennings S, Dulvy NK. 2007. Current and future sustainability of island coral reef fisheries. Current Biology. 17(7):655-658.

Paddack MJ, Reynolds JD, Aguilar C, Appeldoorn RS, Beets J, Burkett EW, Chittaro PM, Clarke K, Esteves R, Fonseca AC, Forrester GE, Friedlander AM, García-Sais J, González-Sansón G, Jordan LKB, McClellan DB, Miller MW, Molloy PP, Mumby PJ, Nagelkerken I, Nemeth M, Navas-Camacho R, Pitt J, Polunin NVC, Reyes-Nivia MC, Robertson DR, Rodríguez-Ramírez A, Salas E, Smith SR, Spieler RE, Steele MA, Williams ID, Wormald CL, Watkinson AR, Côté IM. 2009. Recent region-wide declines in Caribbean reef fish abundance. Current Biology. 19(7):590-595.

Polunin NVC, Roberts CM. 1993. Greater biomass and value of target coral-reef fishes in two small Caribbean marine reserves. Marine Ecology-Progress Series. 100:167.

R Core Team. 2013. R: A language and environment for statistical computing, Vienna, Austria.

Reusch TB, Williams SL. 1999. Macrophyte canopy structure and the success of an invasive marine bivalve. Oikos. 398-416.

Sale PF. 2002. Coral reef fishes: Dynamics and diversity in a complex ecosystem. Academic Press.

Schofield P. 2009. Geographic extent and chronology of the invasion of non-native lionfish (Pterois volitans [Linnaeus 1758] and P. miles [Bennett 1828]) in the Western North Atlantic and Caribbean Sea. Aquatic Invasions. 4(3):473-479. 
436 Schutte VGW, Selig ER, Bruno JF. 2010. Regional spatio-temporal trends in Caribbean coral reef

437 benthic communities. Marine Ecology Progress Series. 402:115-122.

438 SEDAC (Socioeconomic Data and Applications Center). 2010. Global rural-urban mapping 439 project - settlement points. Columbia University, New York.

440 Skaug H, Fournier D, Nielsen A, Magnusson A, Bolker B. 2013. glmmADMB: Generalized 441 linear mixed models using AD model builder. $R$ package version 0.7.7. 4.

442 Snyder WE, Evans EW. 2006. Ecological effects of invasive arthropod generalist predators. 443 Annual Review of Ecology, Evolution, and Systematics. 37:95-122.

444 UNEP-WCMC, WorldFish Centre, WRI, TNC. 2010. Global distribution of warm-water coral 445 reefs, compiled from multiple sources, including the Millennium Coral Reef Mapping Project. 446 UNEP World Conservation Monitoring Centre. Cambridge (UK).

447 Vallès H, Hunte W, Kramer DL. 2009. Variable temporal relationships between environment and 448 recruitment in coral reef fishes. Mar Ecol Prog Ser. 379:225-240.

449 Whitfield P, Hare J, David A, Harter S, Muñoz R, Addison C. 2007. Abundance estimates of the 450 Indo-Pacific lionfish Pterois volitans-miles complex in the Western North Atlantic. Biological 451 Invasions. 9(1):53-64.

452 Whittaker J. 2013. Hunters warned not to feed lionfish to predators. CayCompass. URL: 453 http://www.compasscayman.com/story.aspx?id=127877

454 Willson JD, Dorcas ME, Snow RW. 2011. Identifying plausible scenarios for the establishment of 455 invasive Burmese pythons (Python molurus) in Southern Florida. Biological Invasions.

456 13(7):1493-1504.

457 Wilson DT, Meekan MG. 2001. Environmental influences on patterns of larval replenishment in 458 coral reef fishes. Marine Ecology Progress Series. 222:197-207.

459 Wilson S, Graham N, Polunin N. 2007. Appraisal of visual assessments of habitat complexity and 460 benthic composition on coral reefs. Marine Biology. 151(3):1069-1076.

461 Zuur AF, Ieno EN, Walker NJ, Saveliev AA, Smith GM. 2009. Violation of independence - Part 462 II. In: Mixed effects models and extensions in ecology with R. Springer New York, 161-191. 
464 Figure 1 Coefficient estimates ( $\pm 95 \%$ confident intervals) showing the effect of different

465 variables on lionfish abundance. Lionfish counts were modeled with a generalized linear

466 mixed effect model using the automatic differentiation model builder (glmmADMB) based on a

467 negative binomial distribution type 1 and log link. Abundance values were obtained by adding the

$468 \log$ of survey area as offset in the model. Numerical variables (top axis, circles) and categorical

469 variables (bottom axis, squares) are on different scale for easy visual representation as the

470 magnitude effects of the former are relatively smaller. For full summary of the model see Table

471 S3.

472 Figure 2 Relationship between mean grouper and lionfish biomass. In this study, 71 fore reefs 473 (black dots protected sites, grey dots non-protected sites) were surveyed and analyzed across the

474 Caribbean. For comparison, we included 12 sites (red squares) surveyed at Exuma Cays Land and 475 Sea Park by Mumby et al., (2011). Red fitted line is for the linear regression model by Mumby et 476 al., (2011) that explain $56 \%$ of the variability of lionfish biomass due to grouper abundance.

477 Note that red squares represent $\sim 16 \%$ of all sites. Boxplots are median (vertical or horizontal 478 line), 50 and 90 percentiles for lionfish biomass (right) and grouper biomass (top). Boxplots with 479 black dots (general mean) correspond to our study and boxplots with red squares (general mean) 480 to Mumby et al., (2011). Empty circle are outliers. Axes are in log scale. 
481 Figure 3 Histograms of grouper class size (total length in cm) by categories. A) Class size

482 distribution for protected and non-protected sites, B) for sites with over and under $10 \mathrm{gm}^{-2}$ of

483 grouper biomass, and C) for reef habitat types. Note that over $90 \%$ of protected sites and sites

484 with $>10 \mathrm{gm}^{-2}$ of grouper biomass have individuals $>30 \mathrm{~cm}$ in total length. Only every other class

485 size has a label for clarity.

486 Figure S1 Location of survey sites. For site abbreviations, surveys dates and coordinates refer to 487 Table S1

488 Figure S2 Moran's I similarity spline correlograms for lionfish and grouper raw data across 489 all sites (top two panels) and for the glmmADMB model residuals (bottom panel). Note the

490 strong spatial autocorrelation of the raw data (i.e., swirling lines around zero) and how the

491 hierarchical structure of the random effects (sites nested in regions) of the full glmmADMB

492 model eliminated this correlation in the model residuals. A Mantel test of the model Pearson

493 residuals $(r=0.073)$ corroborates the lack of spatial correlation of the residuals. Lines are the

494 mean $\pm 95 \%$ confidence interval.

495 Table S1 Reef site detailed information. Location names, coordinates, and site characteristics

496 used in the study. S\&G, spur-and-groove.

497 Table S2 Summary of the glmmADMB results. Lionfish abundance (ind. $100 \mathrm{~m}^{-2}$ ) on grouper

498 biomass $\left(\mathrm{g} 100 \mathrm{~m}^{-2}\right)$, predators, and other co-factors. 


\section{Figure 1}

Coefficient estimates ( $\pm 95 \%$ confident intervals) showing the effect of different variables on lionfish abundance.

Lionfish counts were modeled with a generalized linear mixed effect model using the automatic differentiation model builder (glmmADMB) based on a negative binomial distribution type 1 and log link. Abundance values were obtained by adding the log of survey area as offset in the model. Numerical variables (top axis, circles) and categorical variables (bottom axis, squares) are on different scale for easy visual representation as the magnitude effects of the former are relatively smaller. For full summary of the model see Table S3. 


\section{numerical coeffient estimates}

Grouper biomass

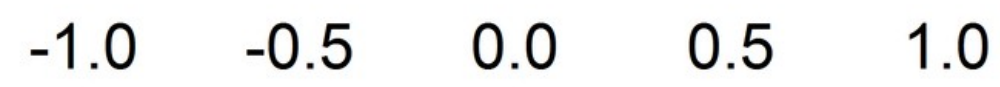

Predator biomass

Humans/Reef

Reef complexity

Time since invasion

Depth

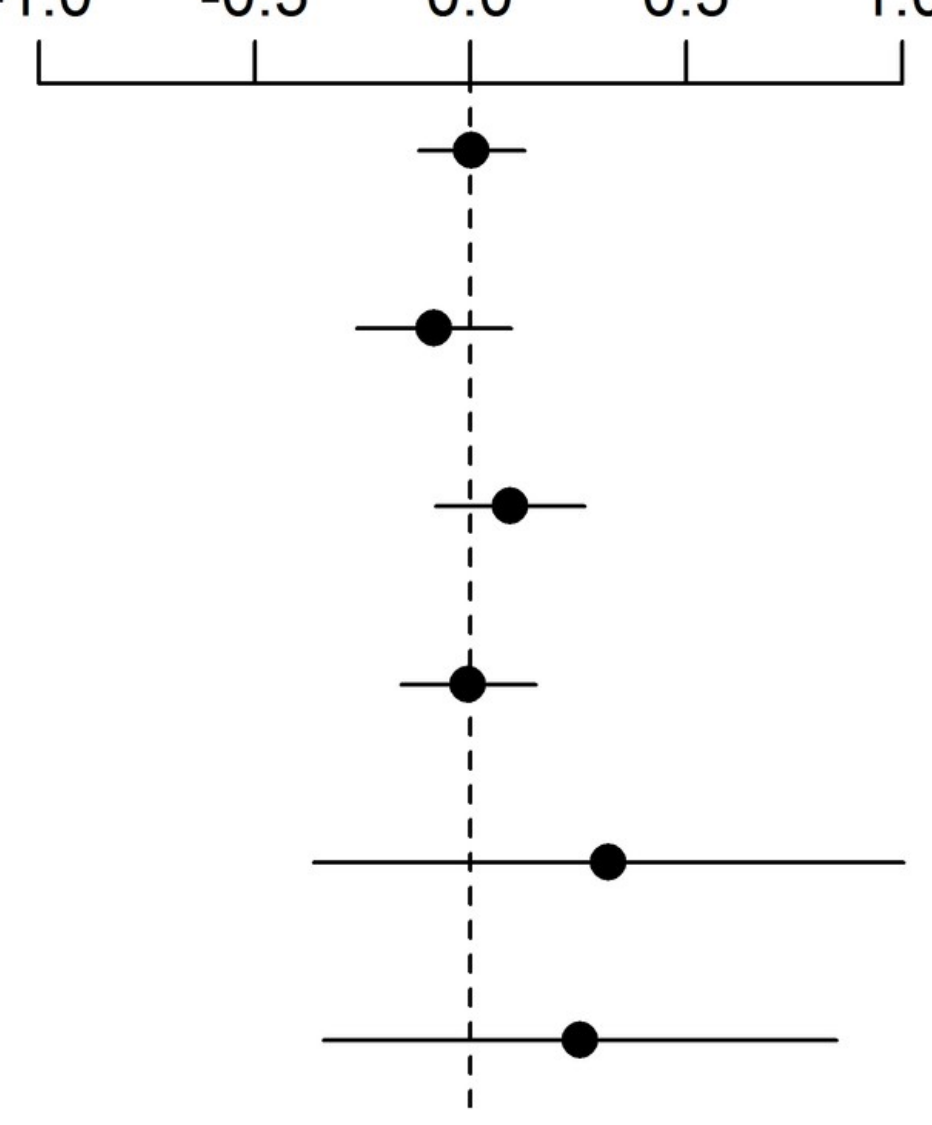

Protected

Winward

Slope

Spur \& Groove

Intercept

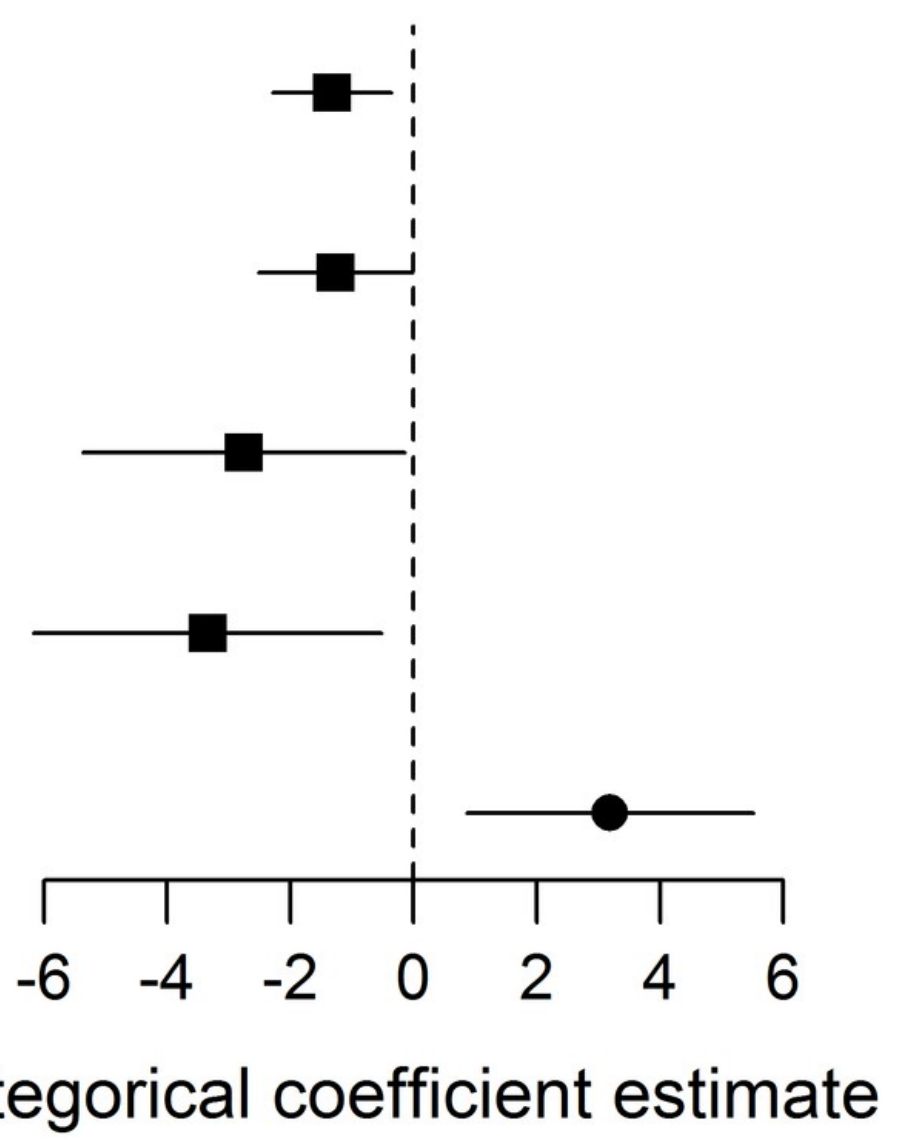




\section{Figure 2}

Relationship between mean grouper and lionfish biomass.

In this study, 71 fore reefs (black dots protected sites, grey dots non-protected sites) were surveyed and analyzed across the Caribbean. For comparison, we included 12 sites (red squares) surveyed at Exuma Cays Land and Sea Park by Mumby et al., (2011). Red fitted line is for the linear regression model by Mumby et al., (2011) that explain $56 \%$ of the variability of lionfish biomass due to grouper abundance. Note that red squares represent $\sim 16 \%$ of all sites. Boxplots are median (vertical or horizontal line), 50 and 90 percentiles for lionfish biomass (right) and grouper biomass (top). Boxplots with black dots (general mean) correspond to our study and boxplots with red squares (general mean) to Mumby et al., (2011). Empty circle are outliers. Axes are in log scale. 


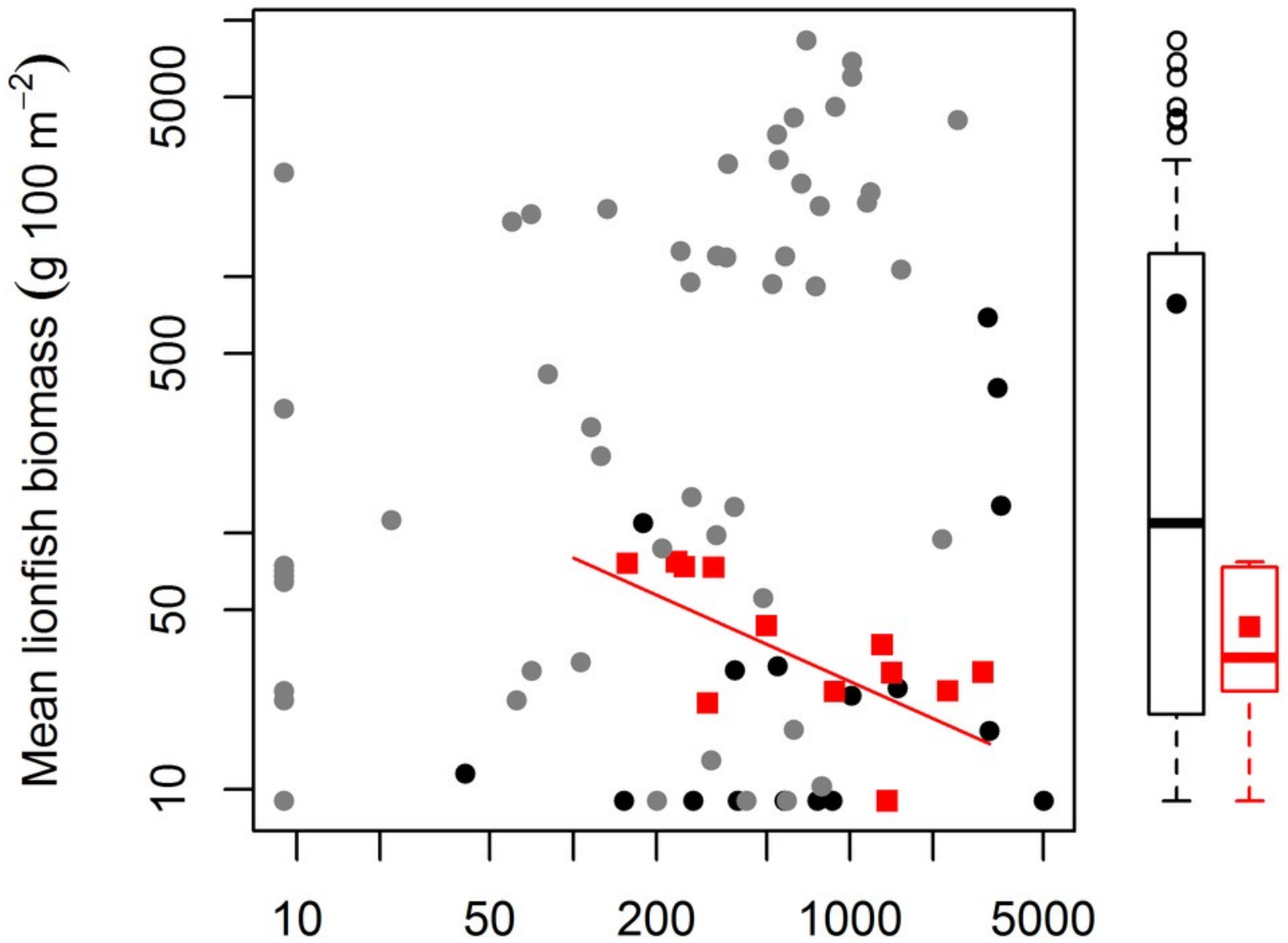

Mean grouper biomass $\left(\mathrm{g} 100 \mathrm{~m}^{-2}\right)$ 


\section{Figure 3}

Histograms of grouper class size (total length in $\mathrm{cm}$ ) by categories.

A) Class size distribution for protected and non-protected sites, B) for sites with over and under $10 \mathrm{gm}-2$ of grouper biomass, and C) for reef habitat types. Note that over $90 \%$ of protected sites and sites with $>10 \mathrm{gm}-2$ of grouper biomass have individuals $>30 \mathrm{~cm}$ in total length. Only every other class size has a label for clarity.
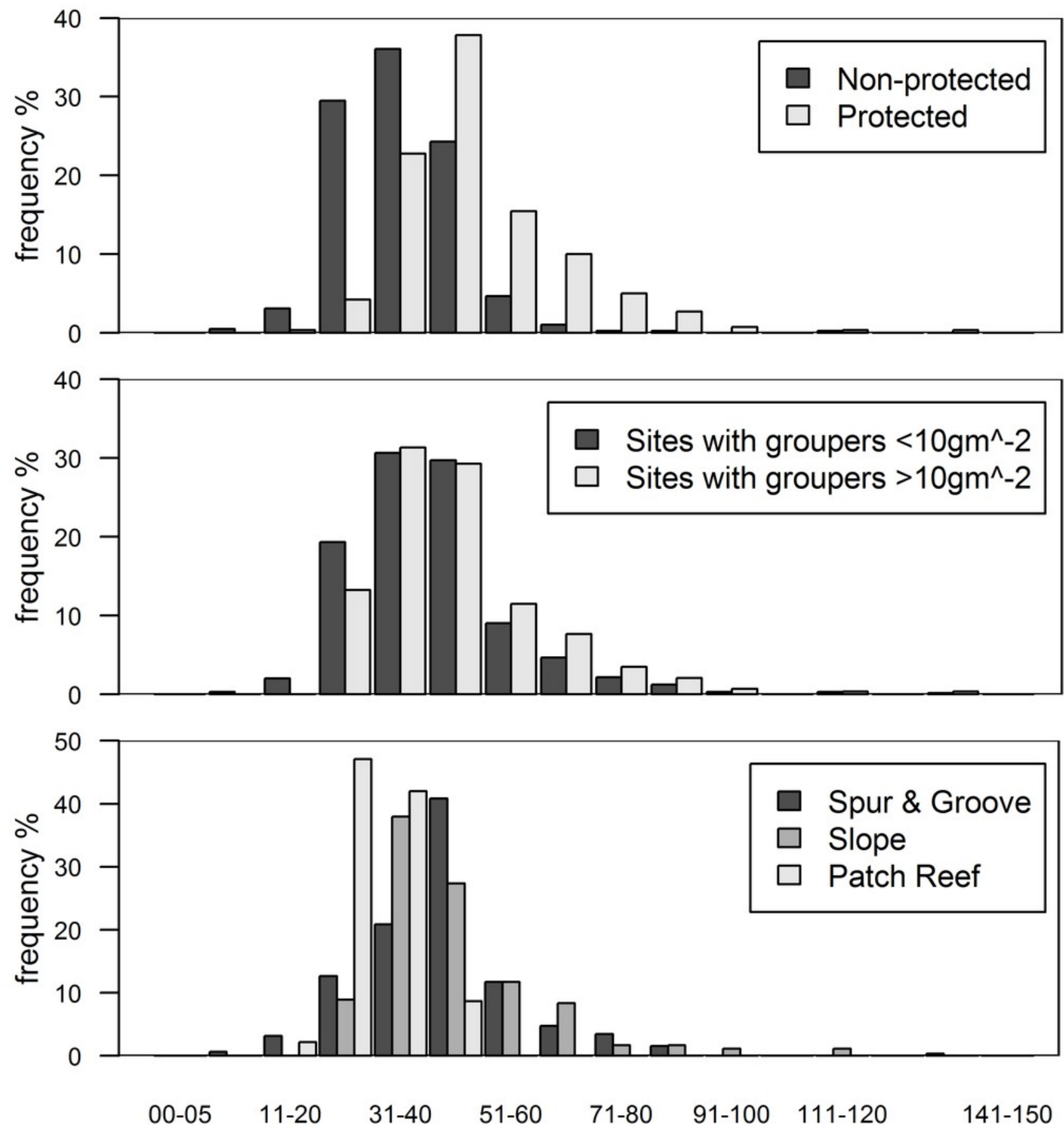